\title{
RUBENS MANO E OS FLUXOS LUMINOSOS
}

Prof $^{\circ}$ Dr. Orlando Maneschy ${ }^{1}$

\section{Resumo}

As relações entre espaço e imagem vêm permeando o trabalho do artista brasileiro Rubens Mano (1960- ) desde suas investigações iniciais acerca do ambiente urbano, ainda na década de 80, quando a fotografia mostrava-se como o único canal de articulação para o artista apresentar suas reflexões sobre tais questões. Sua produção artística se estabelece dentro de um campo no qual questões espaciais e luminosas se instauram para colocar em xeque aquilo que nos é visível. Trabalhando com a transformação do espaço em imagem, Rubens Mano, cuja formação universitária foi na área da arquitetura e urbanismo, articula questões nas quais a luz aparece com elemento de importância fundamental.

Palavras-chave:Arte, imagem, intervenção urbana, fotografia

As relações entre espaço e imagem vêm permeando o trabalho de Rubens Mano (1960-) desde suas investigações iniciais acerca do ambiente urbano, ainda na década de 80, quando a fotografia mostrava-se como canal de articulação para o artista apresentar suas reflexões sobre tais questões. Sua produção se estabelece dentro de um campo no qual questões espaciais e luminosas se instauram para colocar em xeque aquilo que nos é visível.

Trabalhando com a transformação do espaço em imagem ${ }^{2}$, Rubens Mano, cuja formação universitária foi na área da arquitetura e urbanismo, articula questões que relacionam a técnica ao fazer artístico. Aqui a luz aparece com elemento de importância fundamental, pois são espaços nos quais a luz constitui "densidade", por vezes criando situações de estranhamento em imagens, estas mesmas, captadas devido a existência da luminosidade.

Em um destes trabalhos, uma fotografia sem titulo (contra-campo), (1987/2001), exibida pela primeira vez no Panorama da Arte Brasileira - mostra realizada no Museu de Arte Moderna de São Paulo - MAM, em sua edição de 2001 -, uma paisagem de aparência campestre é registrada. Numa cena de "natureza", em meio a arbustos, um círculo branco se inscreve, afetando a paisagem.

O círculo formado na película, quase um recorte na fotografia, que se sobressai na construção da imagem aos olhos do espectador, é proveniente de uma reflexão luminosa a partir de um holofote. Se desconhecêssemos esta intervenção, poderíamos supor que se tratasse da colocação de um objeto diretamente sobre o papel fotográfico, no ato de sua exposição, protegendo essa área do papel do contato com a luz, como em um fotograma, prática empregada por artistas como Man Ray.

Todavia, não se trata de uma intervenção na cópia, mas de impressão na película, proveniente de uma interferência na captação luminosa. Um equipamento de iluminação, um

\footnotetext{
${ }^{1}$ Universidade Federal do Pará/Faculdade de Artes Visuais e Design/ICA/UFPA

2 "Mas um poderia também adicionar que o trabalho se movimenta entre a arquitetura e a fotografia, sem, no entanto, deixar para traz a força com que estas se conectam para revelar a permanente metamorfose do real" SANTOS, Laymert Garcia dos. Rubens Mano: an art of space and its production. Parachute 116 São Paulo. Quebéc: Parachute, 2004. p.27.
} 
holofote, é detectado em meio à vegetação. Da observação do evento, contraste estabelecido entre aparelho e vegetação, surge uma imagem que gera estranhamento devido à sensação de deslocamento propiciada pelo holofote. O que pode aquele tipo de aparelho estar iluminando naquele ambiente de vegetação aparentemente fechada? Um evento que afeta, transitoriamente, a paisagem, com sua emissão de fluxo luminoso, constituindo uma intervenção no espaço.

O espectador da obra - fotografia - pouco ou nada sabe sobre o objeto ou sua intensidade de luz, além do que está registrado na imagem. Círculo, recorte, luminosidade, disco, buraco. Um espaço preenchido por luz que também pode ser um campo de ausência, uma vez que, áreas brancas na superfície do papel fotográfico significam que, naquele lugar correspondente na película fílmica, no negativo, (por reflexão, ou excesso de luz no ato de sua captação), imprimiu-se uma imagem tão densa que, no momento em que a película é exposta para fazer a cópia, a luz é impedida de atravessar estes pontos de densidade.

Podemos ainda pensar, enquanto espectadores, que este holofote se direciona a nós, tal qual no ato do registro da imagem, apontava para o artista.

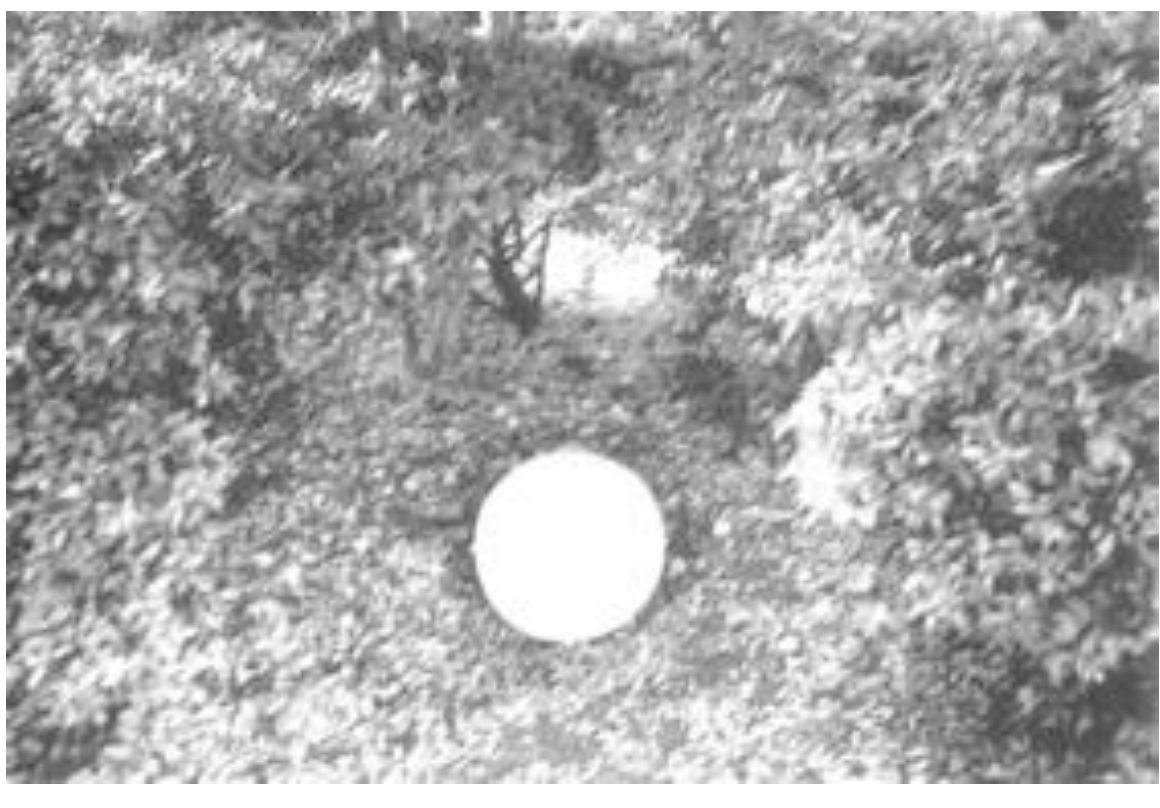

Rubens Mano, s/titulo (contra-campo), 1987/2001

(...) Um círculo de luz branca esburaca a superfície serena da imagem. Entretanto, aqui a emissão de luz que atinge o olhar e concentra a atenção não é um efeito inesperado, mas antes, se expõe abertamente como um acontecimento que afeta e subordina a paisagem. Mais ainda: o foco luminoso não é um reflexo e sim uma reflexão, posto que se trata de um holofote ligado e voltado para o espectador. Assim, em vez de instalar-se um contracampo dentro da imagem, [...] arma-se a partir de um contracampo que tem como centro o observador. Tudo se passa, então, como se o sujeito-objeto da imagem que se vê não fosse aquilo que se encontra à nossa frente, mas sim um corpo real que entrou no raio de ação do holofote e passa a ser por ele iluminado: o corpo do fotógrafo e, também, o do espectador. Presente, embora ausente esse corpo real-virtual se faz imagem fora da imagem, fora do campo, no 
contracampo. De tal modo que a fotografia de Mano parece inaugurar uma formalimite de auto-retrato, pois nele o sujeito pode se mirar sem se ver.

Trata-se evidentemente, de uma auto-imagem mental que o espectador capta na pura reflexão de um raio de luz, de um clarão. [...] A auto-imagem tende a emanar da luz ou nela desaparecer. O que dura é a luz; o que acontece é sua materialização ou desmaterialização ${ }^{3}$.

O holofote de Mano parece apontar para algo que se deseja enfatizar, mas que se encontra fora do campo do registro. O canhão luminoso, posicionado no chão, aponta na direção do espectador. Aqui, o mistério da imagem nos leva à fotografia que enreda a trama do filme Blow-up, de Michelangelo Antonioni (1966), no qual um fotógrafo (David Hemmings) captura a cena de um crime, quando está fazendo inocentes fotos de um casal no parque. Antes de chegar a desvendar o mistério, o personagem tenta descobrir o que poderia haver nas imagens e, ao adentrar, através da ampliação fotográfica, em um fotograma, revela no detalhe, descobre a evidência do crime. O fotógrafo de Antonioni registra sem saber, sem ver, dispara, explode, amplia, revela.

Mano, ao apontar sua câmera em direção do holofote, parece propor um enfrentamento entre a luz e a câmera, sendo atingido diretamente pela luz, registra o ponto do disparo, evidenciado na cópia fotográfica pelo círculo branco. Aqui, é a fotografia a prova, o resultado da relação estabelecida entre um objeto de emissão e uma câmera de captação. Mano insere o observador em sua articulação ao colocá-lo diante da imagem e constituir uma relação entre campo e contra-campo, observador confrontado por algo que não consegue decifrar ao certo, mas que aponta em sua direção.

Este trabalho parece trazer um dado importante para o artista, acerca dos processos engendrados em sua obra, uma vez que a mesma imagem ocupa espaço de destaque em sua exposição individual realizada em $2004^{4}$. A fotografia, posicionada no fundo da galeria, dialoga com as demais obras da exposição, absorvendo o papel de ponto de referência, o "grau zero" do qual o crítico Laymert Garcia dos Santos se refere. A re-inserção da imagem na exposição se dá devido a relação que ela estabelece, enquanto imagem e registro de luz, como se nela estivesse a síntese de toda a produção artística desenvolvida a partir de sua captação. Segundo o próprio Mano:

A importância dessa imagem só vai se confirmando com o tempo [...] A re-inserção dela agora se deu por perceber elementos de trabalhos posteriores a ela, por sugerir toda uma estrutura [...] recuperando coisas. Ela acabou ficando como uma concentração de repertório. Ela não trazia de primeiro todas estas questões, mas com o passar do tempo, ela passa a ter mais sentido do que quando foi produzida ${ }^{5}$.

Holofotes são utilizados na instalação Detector de Ausências (1997), realizada para o projeto Arte/Cidade II, em que Mano atravessa o Viaduto do Chá, em SP, com fachos de luz provenientes de dois grandes refletores, de 12.000 watts de potência. Cada canhão de luz é

\footnotetext{
3 SANTOS, Laymert Garcia dos. Politizar as novas tecnologias: o impacto sócio-técnico da informação digital e genética. São Paulo: Ed.34, 2003. p. 207.

4 Tudo entre nós. Exposição individual de Rubens Mano, realizada na Galeria Casa Triângulo, em São Paulo, nos meses de novembro e dezembro de 2004.

${ }^{5}$ MANO, Rubens. Resposta concedida a Orlando Manescby. São Paulo 20 de mar. 2005.
} 
posicionado sobre torres de cerca de 13 metros de altura, erguidas a partir do Vale do Anhangabaú.

O fluxo luminoso corta o viaduto, em dois fachos paralelos, com 1,5 metros de diâmetro, atingindo de maneira perpendicular o fluxo dos pedestres. $O$ passante, ao atravessar o campo luminoso constituído pela obra, é atingido pelo facho que inscreve sua sombra momentaneamente na paisagem noturna da cidade. O sujeito torna-se, ele mesmo, um índice de impermanência, com a utilização de dispositivos técnicos para a construção plástica do artista, já que não há o objetivo de fixar a imagem, mas de constituir um evento em torno das questões do visível.

Com este tipo de projeto, Mano nos apresenta a própria luz como "matéria" de sua obra, revelando na irrupção do fluxo luminoso, a imagem dos passantes, inscritas no jogo vacilante de luz e sombras.

Os fachos de luz traduzem a velocidade crescente da cidade, desqualificando o espaço, acarretando a desterritorialização. Os rastros luminosos indicam a situação do indivíduo na metrópole: se por um lado a luz permite ver e identificar, por outro também constata o anonimato do indivíduo. As sombras dos caminhantes se projetam sem que lhes seja permitido qualquer registro de sua passagem. Essas figuras não tem mais lugar, seu destino são as trevas, o ilimitado da cidade. Silhuetas dotadas da mesma impalpabilidade dos elementos celestes.

$\mathrm{O}$ viaduto corta o céu e, sobre ele, a multidão parece nuvens. A multidão também não tem desenho fixo, não tem perfil estável, variando sempre segundo o ponto de vista. A instalação aponta para além da idéia da fotografia como documento, tentativa de resguardar as coisas da desaparição ${ }^{6}$.

Desta maneira, o princípio do processo fotográfico constitui a obra, que revela apenas traços fantasmáticos dos passantes, captados em suas silhueta. Este aparato mecânico nos remete aos antigos jogos de ilusão, como lanternas mágicas, ou ainda às máquinas de tomadas de silhuetas ${ }^{7}$, os desenhos fotogênicos. As imagens que surgem com o evento proposto por Mano não são retratos com identidade, nem possuem perenidade, surgem num fluxo de movimentos, rasgando a luz, para desaparecer em segundos na escuridão. São rápidas inscrições na paisagem.

A ausência do desejo de fixação das imagens constituídas a partir de seu dispositivo luminoso parece revelar a inviabilidade de uma permanência desses corpos inscritos na luz, desvelando a dimensão do humano diante da cidade. Rostos, corpos desconhecidos passam a todo instante pelas ruas do centro de São Paulo, utilizando o Viaduto do Chá como mecanismo de acesso entre um lado e o outro do Vale do Anhangabaú. Diferentemente dos processos históricos que utilizaram o fluxo luminoso para registrar um retrato, Mano lança mão do mesmo princípio para revelar que somos figuras anônimas na multidão da metrópole.

\footnotetext{
${ }^{6}$ PEIXOTO, Nelson Brissac. Paisagens urbanas. São Paulo:Senac/Marca D’Água, 1996. p. 42.

7 Toda uma sorte de aparatos óticos foram e ainda são empregados por cientistas e artistas na arte para captar imagens. Máquinas de desenho eram utilizadas para registrar o contorno da figura à partir da projeção de sua sombra, em um papel semi-transparente, graças a uma fonte luminosa. Esse tipo de equipamento se desenvolveu no final do século XVIII, sendo um tipo de retrato de custo mais acessível, devido a sua simplicidade. IN: FRIZOT, Michel. A new bistory of photography. Köln: Könemann, 1998.. p.17.
} 
O evento aponta para uma incapacidade de identificação, na qual o indivíduo se perde ao mergulhar na cidade e transitar em meio à multidão.

O próprio trabalho, ao se confrontar com a escala da urbe, tem suas dimensões diminuídas. Mais ainda, revela, por afirmar sua incapacidade de fixação, de dar conta de algo além do fugidio. São pequenas aparições, passagens breves de estranhos desconhecidos.

A crítica e historiadora da arte Rosalind Krauss, em seu texto Corpus Delicti, aponta para questões que são fundamentais para a relação da matéria e do espaço no qual esta se encontra nos dá pistas interessantes para refletirmos:

Recapitulemos dizendo que diversos métodos fotográficos foram explorados para produzir uma imagem de invasão no espaço: corpos cedendo sob o efeito da vertigem diante da força gravitacional, corpo trabalhando por uma perspectiva deformadora, corpos decapitados pela projeção da sombra, corpos devorados quer pela luz, quer pelo calor. Seguindo as explicações habituais da imagem surrealista, poderíamos dizer que esta consumação da matéria por uma espécie de éter espacial é uma representação da inversão da realidade. [...] Elas não parecem representar corpos pegos do lado interno e transformados, mas antes, corpos assaltados pelo lado externo (... $)^{8}$.

A crítica nos aponta aqui para uma relação da imagem que está mais além daquela que articula com o sonho ou o êxtase surrealista, mas que projeta ao espaço a relação do sujeito que olha, que não está mais "tirando" uma fotografia, uma imagem, mas "criando" uma possibilidade de experiência que articula acerca da visibilidade e que aponta para problema de estrutura do campo da representação.

Em sua dissertação de mestrado, Intervalo Transitivo, Mano articula sua visão acerca das relações entre a paisagem e homem, a arte e a cidade:

Mantida com a construção de uma metáfora (da impermanência), essa correspondência [entre a manifestação cultural da arte e a dimensão simbólica da rua] irrompeu no espaço urbano com a proposta de alterar os processos de verticalização do crescimento constatados na cidade e na arte. Uma imagem muito próxima dos pressupostos críticos e conceituais formulados pelos 'situacionistas' para a revolução do cotidiano - onde a experimentação radical dos lugares da cidade ou mesmo no desenho de uma nova arquitetura, não procurava transformar a vida em 'happenings' ou 'performances', mas superar a dicotomia existente entre a ação artística e os momentos banais do dia-a-dia'.

Com o trabalho intitulado White Cue (1999), cujo termo cue, segundo o artista e de acordo com o Webster's New Worlnd Dictionary, significa uma sugestão indireta, um estimulo secundário que guia determinada ação, que aponta para as relações que o espaço suscitou ao artista.

O projeto de intervenção no espaço consistia em desenvolver um trabalho no subsolo de um restaurante situado nas encostas de um morro no bairro de Santa Tereza, no Rio de Janeiro. O espaço há muito abandonado e com características próprias que revelam a estrutura de sua arquitetura, levou Mano a crer que qualquer ação em seu interior deveria levar em conta as características e condições do lugar. $\mathrm{O}$ artista passou então a estudar a possibilidade de

\footnotetext{
${ }^{8}$ KRAUSS, Rosalind. O fotográfico. Barcelona: Gustavo Gili, AS, 2002, p. 180, 181.

9 MANO, Rubens. Intervalo transitivo. São Paulo, SP, 2003.87p, p.18. Dissertação (Mestrado em Artes). Departamento de Artes Plásticas da Escola de Comunicação e Artes, USP, em 2003.
} 
realizar uma ação que estabelecesse uma relação entre o espaço e as experiências deste: "reveladoras de muitas imagens sobrepostas." 10

Ao pintar o subsolo de branco sem tocar a superfície e sem efetuar uma limpeza prévia, o artista agregou a poeira acumulada, criando instalação que se estabelece como "intervalo" entre o presente, com suas acumulações do passado e possibilidades de futuro. Aí, uma certa configuração material se faz presente, numa tatilidade sutil que reverbera sobre as formas rígidas da arquitetura.

Aqui vale ressaltar que a compleição do espaço com portas e passagens proporciona ao espectador uma experiência que se relaciona com a luz, uma vez que o branco com o qual o ambiente foi pintado propicia uma reflexão luminosa, gerando possibilidades de nuances luminosos a partir do deslocamento do observador pelo espaço.

Também partindo de uma proposição para um lugar específico, o artista realizou a instalação Básculas (2000), utilizando especificidade da arquitetura do prédio da primeira Galeria Casa Triângulo, cujo espaço, localizado no segundo andar de uma construção do início do século XX, repleto de ambientes, como salas, pequenos cômodos, espaços de passagem, apontava para os sinais de seu uso anterior, com a evidência de batentes de portas, pisos policromados, etc. - bem diferente do cubo branco, espaço convencionado, da maioria das galerias de arte.

Mano já observara o lugar antes mesmo de ser representado pela galeria. Passou, então, a pensar o estabelecimento de relações entre suas obras e a arquitetura do lugar, numa articulação entre o espaço enquanto corpo, com seus diversos ambientes e o corpo de sua obra. Para o desenvolvimento da instalação, cuja produção tomou meses, o artista não contou com maquetes ou outro tipo de representação visual. "Pela impossibilidade de conferir seus resultados antes de finalizá-lo, afinal se tratava de uma proposição de uma experiência, o acesso às intenções do projeto era feito somente através de 'projeções mentais'. Se havia indícios de um método de projeto, esse só se realizou virtualmente." 11

Básculas ocupou as seis primeiras salas da galeria, sendo ainda acompanhada de seis ampliações fotográficas ambientadas em um sétimo cômodo, trazendo imagens de outros projetos do artista, como s/título [ da série heucos] (1997), Bueiro [ da série beucos] (1999), Casa Verde (1997) e White Cue (1999). A fotografia, nestes casos, é a maneira empregada por Mano para desdobrar algumas de suas ações. No caso de parte de Básculas, o mesmo ocorre, já que alguns elementos da instalação foram desenvolvidos para aquele espaço específico, tendo na fotografia seu registro e continuação.

Ao pensar em duas antigas portas da Casa Triângulo como básculas, pinta-as com tinta preta de alto brilho e retorna com estas para seus locais originais, propiciando uma ação de movimento e reflexão, dada pelo extremo brilho da tinta, mesmo que se faça sutil pela cor negra. O abrir e fechar, as portas permitem a visão do outro ambiente, o que remete a ação do obturador da câmera fotográfica, que, em forma de cortina negra, abre e fecha, em um tempo determinado, permitindo o contato da luz, que traz a informação visual da imagem que está sendo captada, com a película sensível na qual será fixado o registro.

\footnotetext{
10 Ibid. p. 47.

11 Ibid. p. 56.
} 
O vão existente entre duas salas recebe uma estrutura com espelhos em toda a sua extensão, propiciando uma sensação de ampliação do espaço, devido à reflexão propiciada pelo jogo do espelho. Assim, o artista cria um espaço virtual dentro do lugar no qual o trabalho se situa, desdobrando, ampliando o espaço, projetando-o para dentro do próprio vão.

Este mesmo tipo de relação se estabelece a partir de dois objetos absorvidos na instalação. Fundo (1997), instalado em parede, com espelhos convexos, ferro e borracha, e Sem título (2000), um objeto de aço inoxidável e ferro de proporções generosas. Os dois desdobram-se, ao mesmo tempo em que projetam o espaço expositivo em seu interior.

Em outra sala, um pequeno furo é feito e nele é introduzida uma fibra óptica, para que as cenas do exterior sejam captadas para o ambiente interno da galeria. Princípios ópticos, como o da câmera escura, são acionados nessa instalação. Duas paredes são pintadas com o mesmo tipo de tinta reflexiva empregado para a demarcação de autopistas, propiciando a reflexão de cenas provenientes do exterior do prédio, no Largo do Arouche, constituindo uma espécie de câmara no espaço. $\mathrm{O}$ visitante precisava entrar na sala e permanecer por algum tempo para poder perceber o trabalho. Mano possibilita com isto uma necessidade de vivência temporal por parte do espectador.

Dessa forma, Mano cria condições para que o observador de sua obra se relacione com o ambiente como um lugar da experiência, que só é possível ocorrer se houver um envolvimento por parte do público visitante. Mano, parece nos lembrar de que a experiência óptica visual, ao se revelar, nos apresenta mais do que captamos da realidade. O artista nos leva a perceber o espaço de uma outra maneira, articulando sobre aquilo que é visível, nos levando a crer que a constituição de uma realidade depende de nosso aparato perceptivo. 